\title{
DOS ESCARABEOS DEL SANTUARIO FENICIO DE CAURA EN SU CONTEXTO HISTÓRICO Y ARQUEOLÓGICO ${ }^{1}$
}

\author{
TWO SCARABS FROM THE PHOENICIAN SANCTUARY AT CAURA IN THEIR HISTORICAL AND \\ ARCHAEOLOGICAL CONTEXT
}

\author{
por \\ MARGARITA CONDE ESCRIBANO \\ ROCÍO IZQUIERDO DE MONTES \\ JOSÉ LUIS ESCACENA CARRASCO
}

RESUMEN Entre 1998 y 1999 se llevaron a cabo excavaciones arqueológicas preventivas en el Cerro de San Juan de Coria del Río (Sevilla), emplazamiento de la antigua ciudad de Caura. En estos trabajos se localizó parte de un santuario construido al menos cinco veces entre los siglos VIII y VI a.C. Parece que lo encontrado hasta ahora corresponde a la parte trasera del recinto, si bien los movimientos de tierra pudieron poner al descubierto una capilla pintada de rojo en la que se levantó un altar de barro en forma de piel de toro. Entre los ajuares localizados en el templo se cuentan dos escarabeos de los siglos VII-VI a.C. que constituyen el objeto del presente artículo.

\begin{abstract}
Between 1998 and 1999, preventive excavations were carried out at the Cerro de San Juan of Coria del Río (Seville), settlement of the ancient city of Caura. Throughout the course of these works, part of a sanctuary built no less than five times between the VIIIth and VIth centuries B.C. was localized. The archaeological remains unearthed up to now seem to be the rear part of the enclosure. However, earth movements could have revealed a chapel painted in red with an altar shaped into a bull skin. Among the equipments found in the sanctuary, there are two scarabs dated to VIIth-VIth centuries B.C which are the topic of this paper.
\end{abstract}

Palabras claves Escarabeo, Colonización Fenicia, Mundo Tartésico

Key words Scarab, Phoenician Colonization, Tartessian World

1. Trabajo elaborado en el marco del proyecto BHA 2002-02740 (Ministerio Español de Ciencia y Tecnología) y del Grupo HUM-402 del III Plan Andaluz de Investigación (Consejería de Educación y Ciencia de la Junta de Andalucía)

ISSN: $1133-4525$ ISSN-e: 2255-3924

SPAL 14 (2005): 75-89

http://dx.doi.org/10.12795/spal.2005.i14.03 


\section{CAURA Y SU SANTUARIO DE BAAL}

En los momentos álgidos de la colonización fenicia arcaica del mediodía ibérico, la desembocadura del Guadalquivir difería bastante de la de hoy. En relación con el mundo antiguo en general, la fuente más clara a este respecto es la Geographía de Estrabón (III, II, 4-5), que habla de un ambiente palustre de esteros e islas. Pero no faltan informes que aluden a situaciones anteriores y que sugieren que, lo que en tiempos romanos se conoció como lago Ligustino - una especie de albufera- antes fue una verdadera ensenada marina: el sinus tartesicus (Avieno 265-306).

En época reciente, los estudios geológicos pioneros que intentan perfilar la antigua línea de costa se deben J. Gavala (1959). En ellos se propone un contorno litoral protohistórico con base en datos geológicos y topográficos, en tanto que ciertas curvas de nivel darían la clave para dibujar el litoral que encontrarían los fenicios al arribar a Tartessos. Posteriormente, dos nuevos aportes han reivindicado la geología para solventar este problema: la tesis de L. Menanteau (1982) y los sondeos llevados a cabo por el Instituto Arqueológico Alemán (Arteaga y otros 1995). Receptivos a sus resultados, los arqueólogos tienen ahora más fácil la ubicación de ciudades y sitios nombrados en las fuentes escritas de la época, que hacen referencia lógicamente a una geografía diferente de la actual.

Todas estas labores han definido una antigua bahía que ocupó la actual comarca de Las Marismas (fig. 1). En ella desembocada el Betis mucho más arriba -al menos setenta kilómetros en línea recta- de donde lo hace ahora. Desde las playas de Matalascañas y desde Sanlúcar de Barrameda, el golfo se abría en forma triangular hasta alcanzar su vértice septentrional en Coria del Río (Caura). A partir de aquí, y hasta la antigua Ilipa (Alcalá del Río), se prolongaba la verdadera ría, que luego el Guadalquivir ha rellenado con aluviones hasta convertirla en una vega atravesada por su cauce histórico.

En torno al golfo tartésico, el poblamiento más denso corresponde a la costa oriental, donde la fertilidad del suelo permitió extensos enclaves urbanos: Asta Regia, Nabrissa, Ugia, Conobaria, etc. En el litoral de poniente, con terrenos más pobres, se conocen muchos menos asentamientos, destacando los sitios de San Bartolomé (Almonte) y Chíllar (Villamanrique de la Condesa). Cuando el mar comenzaba a hacerse estuario fluvial a la altura de la vieja desembocadura bética, dos importantes ciudades se ubicaban en sus orillas: Orippo al este y Caura al oeste.

Entre Caura e Ilipa, puntos extremos del paleoestuario del Guadalquivir, nació Sevilla en el siglo VIII a.C., con un nombre (Spal>Hispalis) en parte (Correa 2000) o por completo (Díaz Tejera 1982: 20; Lipinski 1984: 100) relacionado con su fundación fenicia².

De la situación arqueológica que hoy conocemos, incluidos los hallazgos recientes en el Carambolo, se infiere que los colonos semitas mostraron un alto interés por asentarse en la mayor entrada fluvial hacia los territorios tartésicos, con la implantación de un contingente humano que sigue el modelo usado, por ejemplo, en la propia Gadir: creación de asentamientos comerciales y habitacionales, dedicación de ciertos espacios a necrópolis y consagración de edificios de culto a sus principales dioses. De esta forma, los fenicios habrían conseguido diseñar en la ría bética de entonces un paisaje al más puro estilo colonial entre una escasa población indígena integrada en dicha estructura como masa social sometida.

Al sur de Spal, y controlando la margen derecha de la paleodesembocadura del Guadalquivir, el asentamiento de Caura había conocido una importante ocupación prehistórica que se remonta a la Edad del Cobre al menos, si bien el sitio parece que quedó desocupado en la segunda mitad del segundo milenio a.C. En la ciudad protohistórica, que se desarrolló sin solución de continuidad durante todo el primer milenio a.C., se instaló también una pequeña comunidad cananea. A esta fase corresponde la aparición, en la parte hasta ahora excavada del yacimiento, de las primeras construcciones sólidas con

2. En contra de esta hipótesis véase Sanmartín (1994: 230), que rechaza su posible significado semita de lugar bajo y costero precisamente por basarse en la geografía actual. 


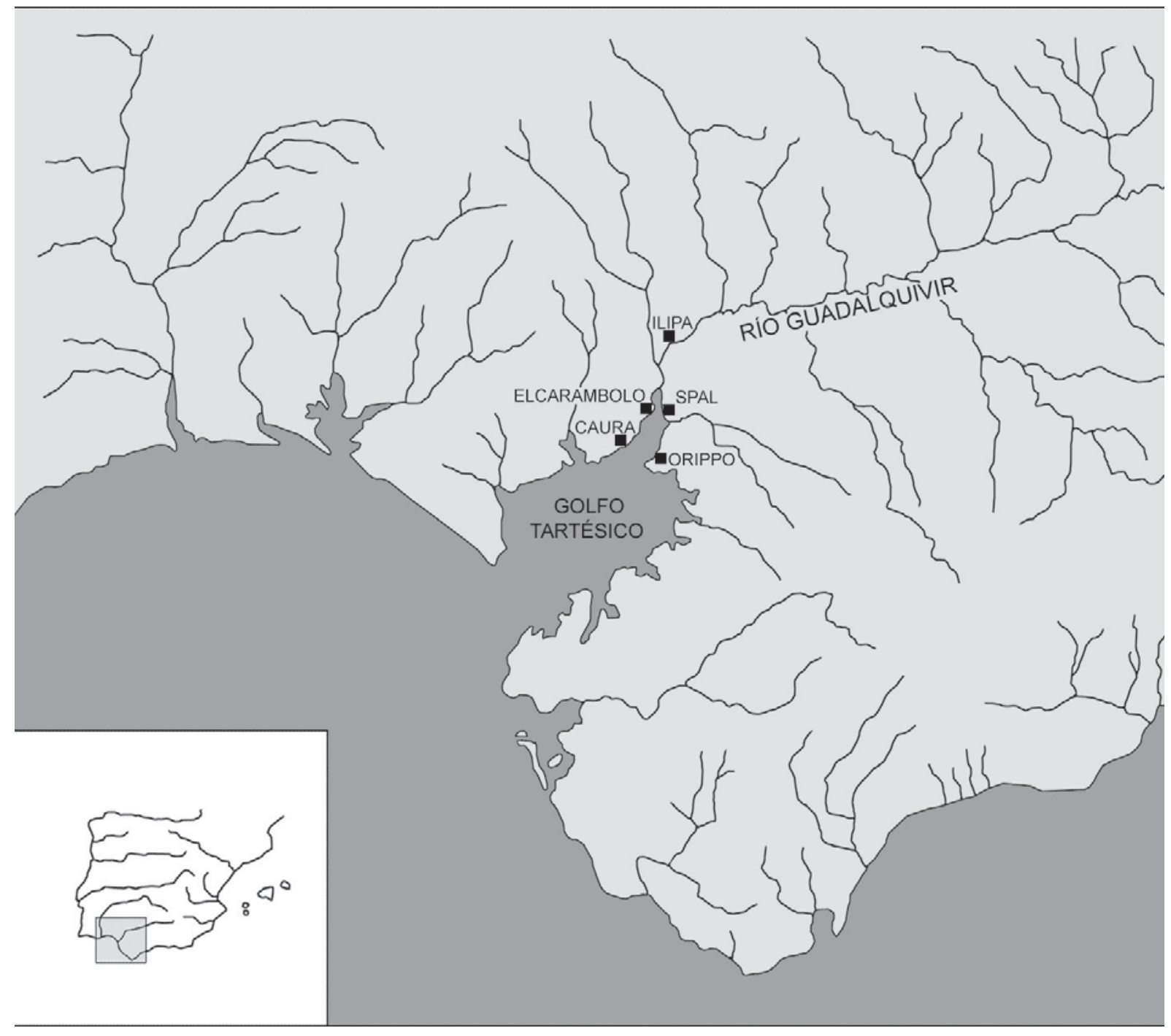

Fig. 1. Reconstrucción de línea de costa de Andalucía occidental

cimentos-zócalos de piedra y alzado de adobes, y sobre todo la expansión del hábitat con la fundación de un templo y de un barrio que se ordena en damero a su alrededor.

La superposición de cinco estructuras con similar diseño en la expansión de la ciudad hacia el oeste, sugiere que todas ellas pudieron tener la misma función, de manera que la identificación de una de ellas como santuario permite extender este papel a las otras cuatro. Desde la más antigua (I) a la más reciente (V) se produjeron algunas modificaciones, pero nunca tan profundas como para pensar en su abandono como lugar de culto. Sólo el edificio más reciente, que conoció una reducción de su superficie, podría arrojar algunas dudas al respecto.

La construcción que muestra con más claridad su utilidad cultual corresponde al Santuario III, del siglo VII a.C. En él apareció una estancia pavimentada con un suelo rojo y adosada al muro de cierre del templo, con un banco de barro paralelo a esta misma pared y con un altar en el centro en forma de piel de toro (fig. 2). El tipo de altar construido en Caura es ya relativamente abundante en la protohistoria meridional ibérica, y caracteriza a centros de culto de carácter tanto rural como urbano. Muestra del 


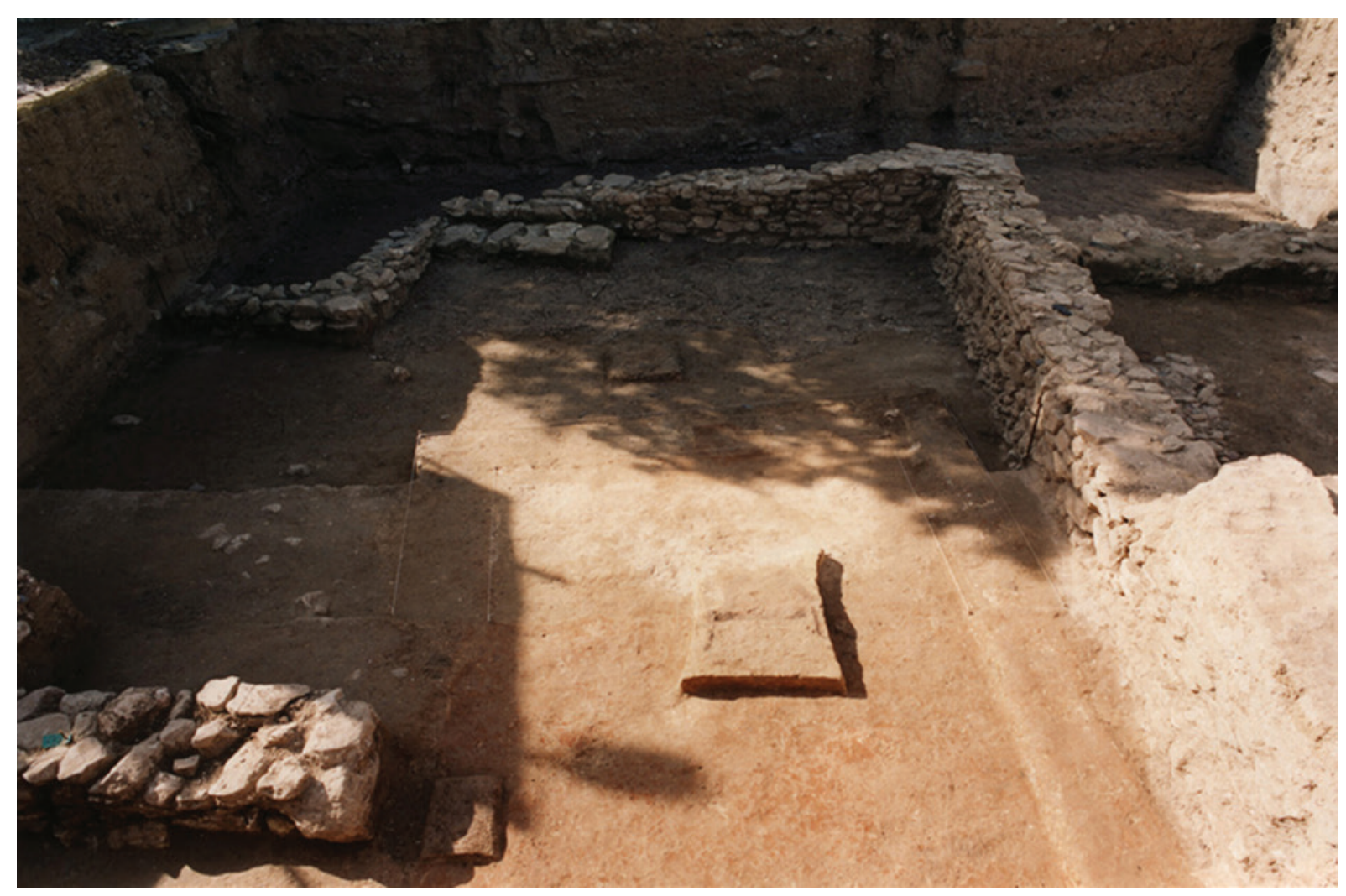

Fig. 2. Santuario III de Caura. En el centro de la capilla pintada de rojo, el altar en forma de piel de toro en su fase más moderna

primer caso puede ser el santuario de Cancho Roano, en Extremadura (Celestino 1997), mientras que resulta un buen ejemplo del segundo el del Oral, en la provincia de Alicante (Abad y Sala 1993). Aunque el de Caura pertenece al modelo urbano, la topografía del Cerro de San Juan -nombre actual de sitiosugiere cierta proximidad del recinto a la subida más fácil al cabezo, es decir, una manifiesta cercanía a la principal puerta de la ciudad.

El santuario de Caura fue un recinto abierto delimitado por un muro. Pudo tener su acceso principal por la fachada oriental, pero se desconoce este extremo. Es posible que dispusiera de otro en la cara opuesta -la excavada-, donde se constata un retranqueo a manera de pórtico del muro de cierre; pero estos vanos de entrada y salida no se reflejaron en la cimentación de piedra, que es la única parte conservada del perímetro del edificio. Este mismo hecho caracteriza a las casas vecinas, y tuvo por misión evitar zonas especialmente débiles en los fundamentos de la obra (Escacena e Izquierdo 2001: 146). El templo pudo disponer por tanto de dos puertas, si bien algunas cuestiones rituales sobre su orientación astronómica sugieren una mayor importancia para la de levante.

Los pavimentos de tierra pintados de rojo indican que el templo tuvo partes cubiertas. De lo contrario, la intemperie habría destruido estos delicados suelos. La norma constructiva, por tanto, era empedrar sólo los ámbitos que no disponían de techumbre, es decir, los patios, sobre todo para impedir lodazales en tiempos de lluvia. Las áreas abiertas enlosadas caracterizan a distintas fases del edificio, pero junto a ellas siempre existieron otras preservadas por techos cuyas características desconocemos.

El ámbito más sagrado hasta ahora detectado corresponde a la capilla del Santuario III en la que apareció el altar en forma de piel de toro, del siglo VII a.C. Se trata de un pequeño recinto que debió 
estar cubierto, aunque no tuvo paredes en sus cuatro costados. La presencia de fuego en el altar haría necesaria una buena ventilación de la estancia, con lo que quizás fuera un sector protegido de las inclemencias meteorológicas sólo por un cobertizo. La ausencia de muros en sus lados sur y oeste avala esta hipótesis. Sobre su piso de tierra asentada y pintada de rojo se levantó un banco de escasa altura -sólo unos $10 \mathrm{~cm}$-adosado a la tapia perimetral del santuario. Este asiento se hizo también de barro y se pintó de rojo como el pavimento.

Desde su construcción, el altar no quedó paralelo a la pared del templo ni al eje longitudinal de la capilla. En cambio, esta disposición es la misma que la del primer santuario. La evolución topográfica y urbanística del asentamiento explica que los cuatro santuarios superiores dejaran de mirar al sitio que canónicamente debían hacerlo, al que se orientan el Santuario I y el altar del edificio III. Ese horizonte debía marcar una fecha importante en el calendario, porque ambos elementos disponen de un eje que discurre desde el orto solar del solsticio de verano al ocaso del de invierno. Esta misma característica se manifiesta en el altar recientemente descubierto en el Carambolo. Pero, aparte de estas cuestiones astronómicas, que hablan de su vinculación solar y de su relación por tanto con una divinidad masculina omnipotente, el altar de Caura contiene singulares características que denotan el profundo significado simbólico de su forma y de sus colores.

Aunque puede hablarse hoy de una sola pieza, en realidad está compuesto por dos aras embutidas, porque la más reciente (B) aprovecha la antigua (A) y la renueva (fig. 3). Consistió en una plataforma de barro de tendencia rectangular con los lados cóncavos. Primero se levantó un paralelepípedo de tierra de color castaño, que luego se rodeó de un enlucido de arcilla amarillenta. En uno de los lados menores, el que mira al este, se añadió un pequeño receptáculo delimitado por un cordón del mismo barro amarillento. Todo el conjunto y la capilla que lo contenía se pintaron finalmente de rojo, excepción hecha
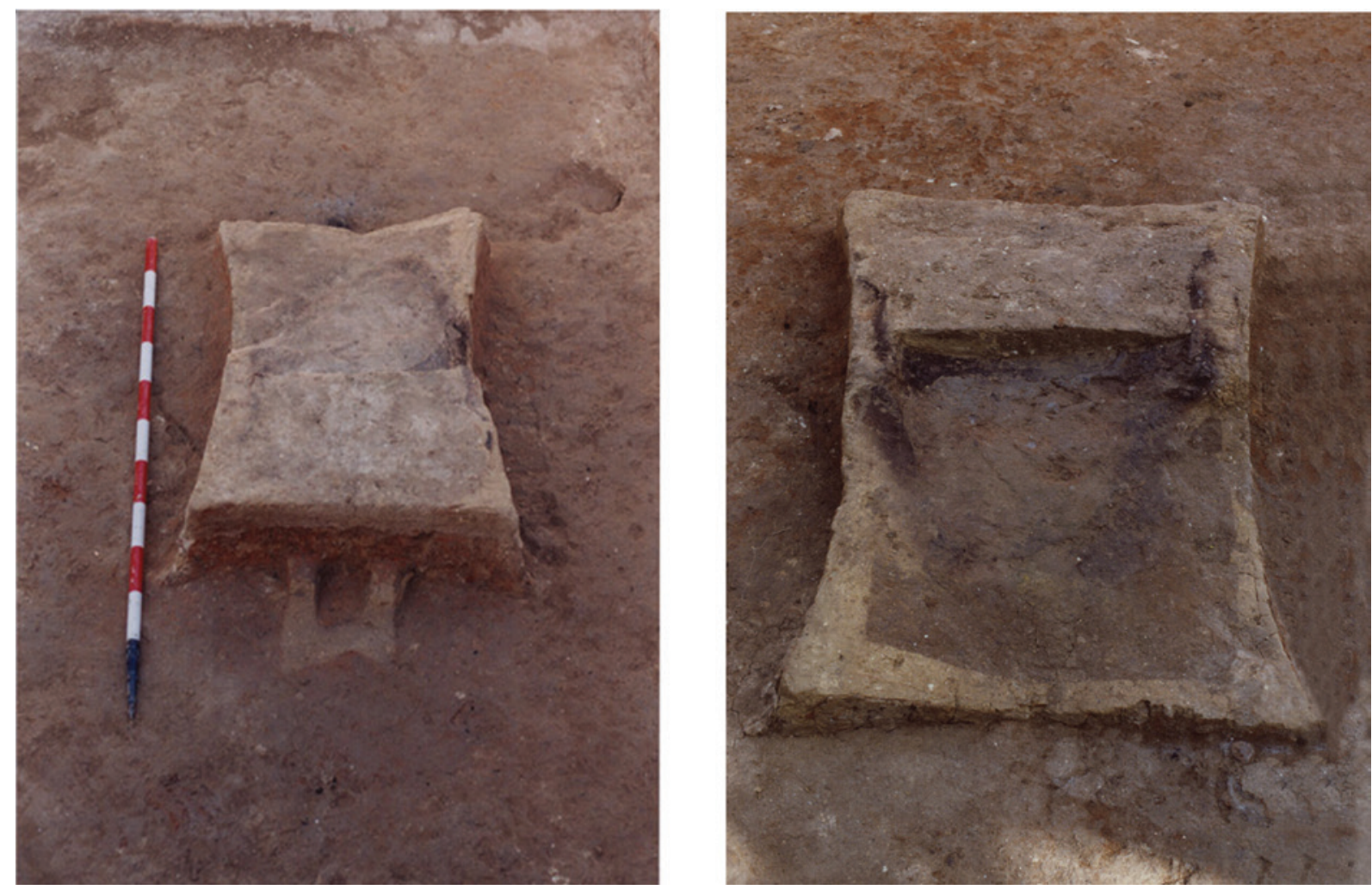

Fig. 3. Altar del Santuario III en sus momentos antiguo (izquierda) y reciente (derecha)

ISSN: 1133-4525 ISSN-e: 2255-3924

SPAL 14 (2005)

http://dx.doi.org/10.12795/spal.2005.i14.03 
de la plataforma superior del altar, que debía mostrar el contraste cromático entre el rectángulo central y la periferia en recuerdo de su significado. Sobre esta superficie se llevó a cabo la incineración de las ofrendas, lo que endureció una ligera concavidad que dibuja el hogar. El uso prolongado de la capilla deterioró su suelo, con lo que se procedió en determinado momento a elevar el piso y a echar una nueva película de arcilla bermeja. Este arreglo ocultó la protuberancia del flanco oriental del altar, que no se volvió a reconstruir más. En conjunto, el ara se usó básicamente durante el siglo VII a.C. Su primera fase (A) conoció así una planta muy singular, que ha proporcionado importantes claves para su interpretación simbólica y que no responde por completo a la forma que a partir del siglo VI a.C. se generalizaría en otros altares de los santuarios protohistóricos hispanos, que siguen el modelo de la fase B.

Se ha pensado en la similitud entre estos altares y las pieles de toros (Celestino 1997: 372). No obstante, por lo común se han tenido por imitaciones de los lingotes de cobre, quizás en parte por la existencia en Chipre a fines del segundo milenio a.C. de una divinidad supuestamente relacionada con el lingote y que recibía culto en Enkomi (Ionas 1984: 102-105); de ahí el nombre genérico con el que se les conoce: «altares en forma de lingote». Los detalles la pieza de Caura hablan empero de la imitación directa de las pieles de toros. Su silueta y sus colores corresponden a las características reales que éstas presentaban en la Antigüedad después de su curación, estableciendo así un fuerte vínculo con la epifanía animal de la divinidad al que el altar estaba consagrado.

En egipcio medio, por ejemplo, el ideograma alusivo a «piel de toro» es un esquema de la forma de estos altares de barro, si bien dicho signo presenta un apéndice inferior correspondiente a la cola del animal desconocido en los altares (cf. Gardiner 1982: 464). Pero la imagen más fiel de cómo se preparaban las pieles de toros y cabras, o las zaleas de ovejas, la ofrecen las representaciones de las sillas de montar de los caballos. Así, se procedía primero a recortarlas para darles forma aproximada de X, siendo los extremos del aspa las zonas correspondientes a las cuatro patas del animal desollado. Luego se delimitaba en el centro una zona que conservaba el pelo, mientras que la franja externa se rasuraba. El contorno adquiría así el color amarillento que tienen los pellejos de panderos y tambores. El Egipto antiguo plasmó con detalle estas pieles con el rectángulo central de pelo y los bordes rapados (Delgado 1996: fig. 81). Es más, algunas de estas monturas para caballerías presentaban en su parte delantera una lengüeta correspondiente a la piel del cuello del animal, y que puede identificarse con la protuberancia que tuvo el altar más viejo de Caura en su lado oriental ${ }^{3}$. Parece que en este caso se imitó la piel de un toro castaño.

Gracias a esta estrecha emulación, es ahora mucho más evidente que los «frontiles» del tesoro del Carambolo concentran en su silueta y decoración suficientes claves para una similar identificación. Estos objetos se conocen en la literatura arqueológica como "pectorales" en razón de la primera función que se les atribuyó; pero no hay imágenes en el mundo antiguo que apoyen ese papel. En cambio, sendas piezas escultóricas en piedra procedentes de Villajoyosa, en España (Llobregat 1974), y de Lattes, en Francia (Py y Dietler 2003), sugieren su colocación en el testuz de los toros ofrecidos a los dioses. Les conviene más, por tanto, el término «frontiles», usado en algunas romerías españolas para el atalaje que adorna las cabezas de los bóvidos que participan en ellas (Amores y Escacena 2003: 20). Los dos del Carambolo reflejan con exactitud cómo se trabajaban las pieles de toros. A pesar de su esquematismo y alto grado de abstracción, exhiben la silueta del cuero del animal y el reborde libre de pelo, y en última instancia el trozo de piel correspondiente al cuello, convertido ya en una protuberancia de significado desconocido antes del hallazgo del altar de Caura. Diversos autores han advertido la presencia en origen

3. Para matar a los bóvidos, en la Antigüedad se degollaban, no se apuntillaban. Es lógico que la palabra que en ugarítico se refiere a cuello se relacione con elementos de muerte. Así, npšn (sepultura) tiene que ver con npš (garganta). Por aquí perdían la vida los animales sacrificados, y por tanto era éste el lugar de residencia del alma (Del Olmo 1998: 51 y nota 44). Es posible que el hueco que en este sitio presenta al altar de Caura estuviese destinado a depositar sangre de la víctima. 


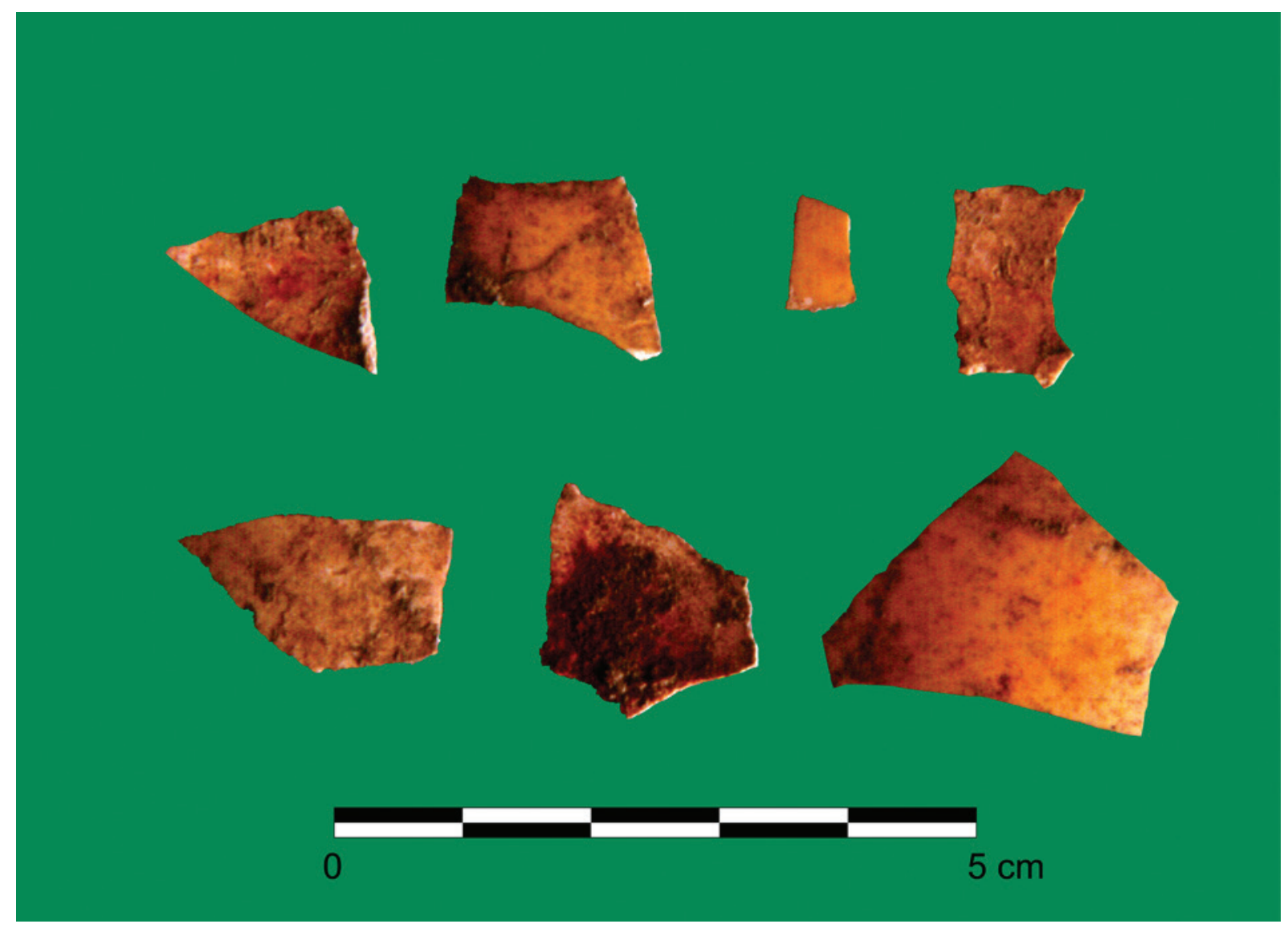

Fig. 4. Cáscaras de huevos de avestruz de distintos niveles del Santuario de Caura

de este apéndice también en el ejemplar que hoy carece de él (Kukahn y Blanco 1959: 39; Carriazo 1973: 130; Perea y Armbruster 1998: 127), de manera que en origen se trataría de dos piezas idénticas en su forma.

El carácter sagrado de este edificio de Caura se sustenta en otros hallazgos propios de ambientes templarios: dos escarabeos de los siglos VII-VI a.C. - piezas que estudiaremos a continuación- y algunos fragmentos de cáscaras de huevos de avestruz. El escarabeo azul apareció entre las piedras de un pavimento del Santuario III; el otro, de pasta blanca, en la periferia de un estrato de cenizas que se originó a consecuencia de la acumulación de los restos de ofrendas quemadas en el templo mientras estuvo en uso el Santuario IV. Las cáscaras de huevos de avestruz proceden de diversos contextos. Muchos presentan restos de ocre por su interior por haber servido como polveras rituales (fig. 4).

Años antes de la excavación de este conjunto de edificios superpuestos, una inspección ocular del yacimiento pudo constatar la existencia de grandes piedras perforadas que se consideraron posibles anclas. De este dato, así como del texto de Avieno que cita en la desembocadura del río Tartessos un sitio denominado Mons Cassius, M. Belén (1993: 49) propuso la existencia en este cabezo de un templo consagrado a Baal Saphon. Puesta a prueba en distintas ocasiones, esta hipótesis es de momento la que más datos explica. Su confirmación permitiría sostener que el interés de los fenicios por este tramo inferior del Guadalquivir les llevó a dibujar un territorio que incluía la presencia en Caura de una comunidad propia y de un templo consagrado a la divinidad patrona de la marinería, un pequeño grupo de colonos que dispuso de su correspondiente necrópolis en la parte meridional del vecino Cerro de Cantalobos, al 


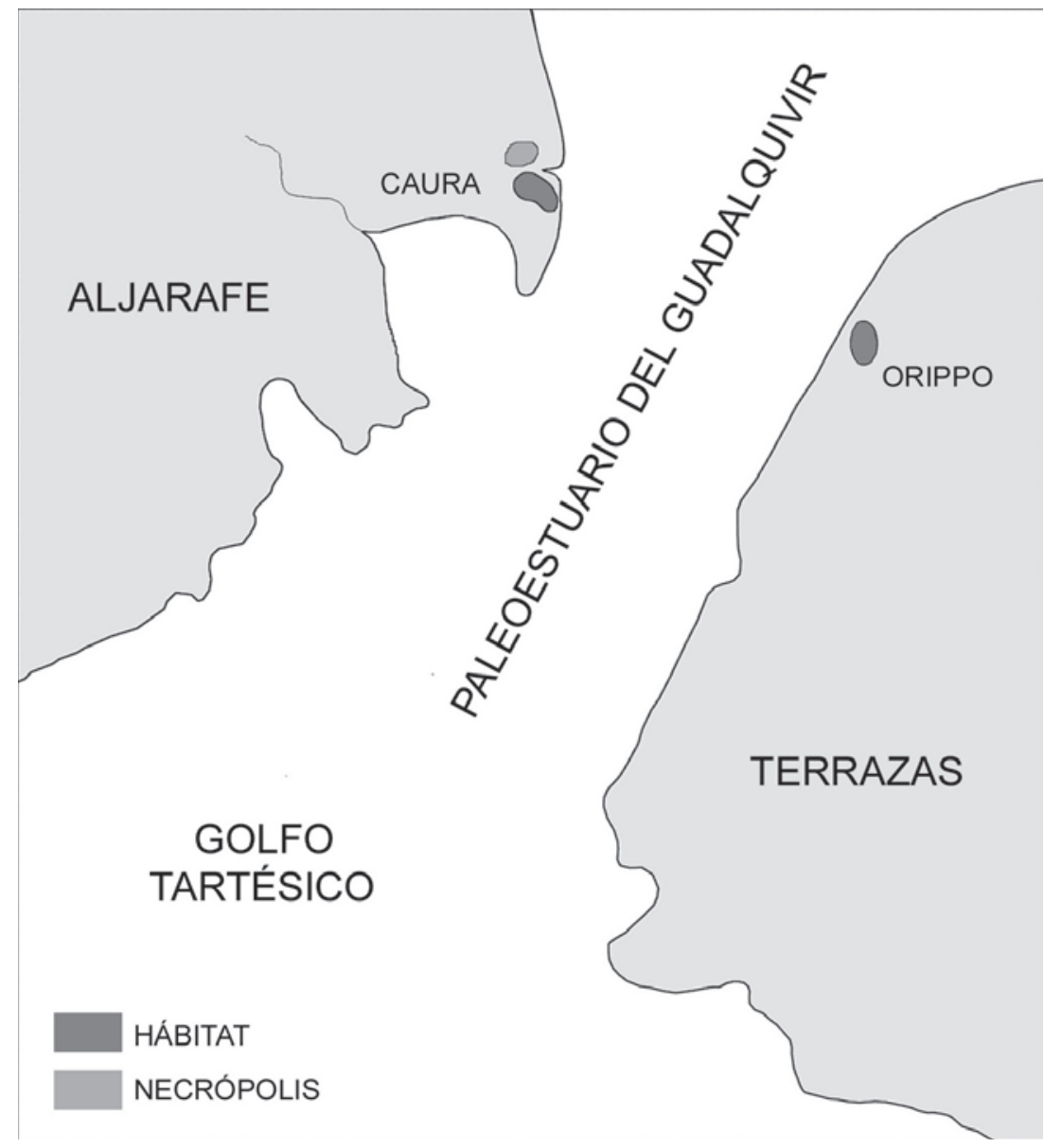

Fig. 5. Situación de Caura (Cerro de San Juan) y de su necrópolis del Hierro Antiguo (Cerro de Cantalobos) en el contexto de la antigua desembocadura del Guadalquivir

noroeste de la ciudad (fig. 5). Se trataría, en definitiva, de la instalación de un verdadero port of trade al modo como ha sido definido para otros grupos humanos de época antigua (Polanyi 1975; Revere 1976: 99-101).

\section{LOS ESCARABEOS DE LOS SANTUARIOS III Y IV}

\section{Pieza 1. El escaraboide azul del Santuario III}

Por faltarle los detalles anatómicos del animal en su cara superior, se trata en realidad de un escaraboide (fig. 6). Mide 13,5 mm de largo, 10,5 mm de ancho y $7 \mathrm{~mm}$ de grosor. Se hizo con pasta artificial homogénea de color azul. Apareció roto longitudinalmente, con una fisura que lo abrió en dos partes en el momento de su extracción. Al parecer, en su día se perdió entre las piedras de arenisca de un pavimento del Santuario III. Aunque dicho empedrado fue cortado por la zanja de cimentación del muro perimetral del Santuario IV, estas remociones no afectaron al área donde se halló el escarabeo (fig. 7), de manera que puede atribuirse sin lugar a dudas al Santuario III, aunque a un momento en que el altar en forma de piel de toro no estaba en uso, porque había sido ya amortizado y colmatado por diversos niveles arqueológicos. 
Fig. 6. Escaraboide azul del

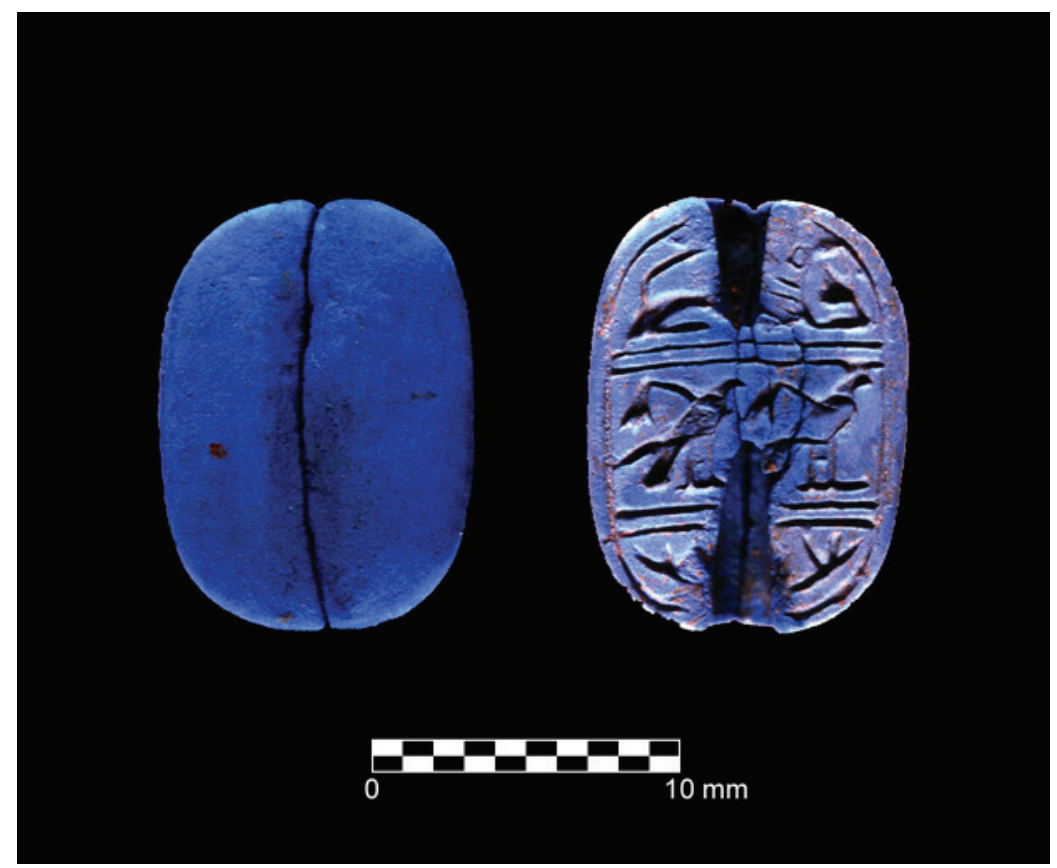

Santuario III

Es un ejemplar de forma ovalada, del tipo escaraboide con forma de "pastilla", con perforación longitudinal. El anverso es liso, carente de decoración. Por el contrario, el reverso está dividido en tres registros, separados y definidos por una doble línea incisa, todo ello enmarcado por una ranura simple de planta oval. La fractura desarrollada a lo largo del eje de perforación, por donde la pieza era más débil, ha dañado considerablemente los registros superior e inferior, dificultando en parte la identificación de sus motivos iconográficos.

El primer registro está decorado con lo que parece un animal de cuerpo felino tumbado y mirando a la derecha, con la cola arqueada hacia arriba y una especie de flor de loto entre las zarpas delanteras, como otros ejemplares hace tiempo publicados (cf. Vercoutter 1945: $\mathrm{n}^{\text {os }} 406,410$ y 574). La figura parece una esfinge o un grifo, aunque resulta difícil de precisar por la fractura que la recorre verticalmente por el centro. El segundo registro está decorado con dos halcones con flagelo. El tercer registro presenta también dificultad a la hora de precisar su decoración a causa de la referida fisura. Los motivos que se aprecian parecen flores de loto y bien se podría suponer que el elemento central que falta corresponde a una especie de flor de papiro o palmeta según es frecuente en motivos orientalizantes representados en marfiles de la misma época (cf. Aubet 1979: fig. 6, n 14). Los motivos que decoran la base están realizados mediante incisión profunda para los contornos y líneas, y corte para los cuerpos.

La pieza, de tipo egiptizante, puede pertenecer al grupo de escarabeos y escaraboides $\mathrm{n}^{\circ} \mathrm{XXVI}$ de Gorton (1996: 85-88), bien definido en asentamientos fenicios y púnicos del Mediterráneo central y occidental, especialmente en Cartago, una variedad que, por lo demás, apenas cuenta con paralelos en Levante o Egipto (Gorton 1996: 80 y 88). En líneas generales, este tipo se caracteriza por una serie limitada de motivos: una esfinge o un disco solar en el registro superior, un halcón con flagelo junto a una divinidad o flores de loto en el campo medio, y un cesto neb en el registro inferior (cf. Vercoutter 1945: $\mathrm{n}^{\text {os }}$ 247-253, 404 y 452; con otros motivos $\mathrm{n}^{\text {os }} 254-264$ ). Los temas iconográficos de esta pieza de Caura concuerdan perfectamente con tales directrices generales, aunque presenta ciertas peculiaridades que la diferencian a la vez. 


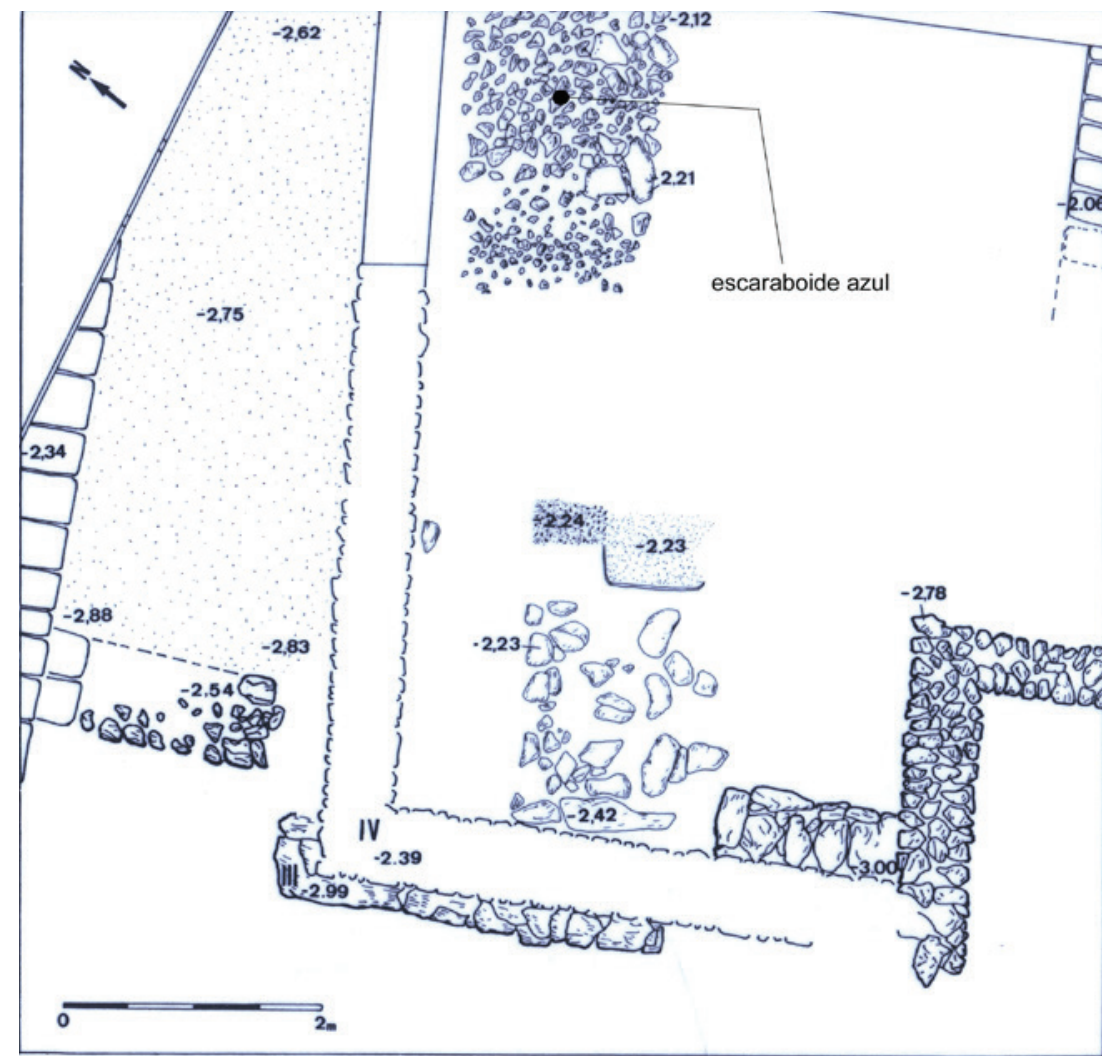

Fig. 7. Lugar de hallazgo de la pieza 1

El animal con cuerpo de felino que ocupa el campo superior podría ser perfectamente una esfinge con cabeza de ave, aunque la fractura no permite afirmarlo con rotundidad. Dos elementos anómalos llaman la atención: el ojo almendrado y las líneas del cuello a modo de collar. Ambos caracteres plantean la posibilidad de identificar a este ser con un grifo de tipo egeo (cf. Bisi 1965: 104 y 193-194).

En el registro central suele estar presente un halcón con flagelo combinado con otro motivo diferente. En este ejemplar son dos los halcones representados. Se podría decir que uno es el calco del otro. No sólo están dispuestos de igual forma sino que la talla es casi idéntica en ambos casos. Resulta sugerente la similitud del diseño del flagelo con la flor de loto, de gran tamaño y con extremo abierto en tres puntas.

El campo inferior también plantea problemas a la hora de identificar el motivo a causa de la fractura ya mencionada. Es seguro que no se trata del típico cesto neb que decora generalmente esta parte de las piezas del grupo, sino de un motivo floral del que sólo se aprecian con claridad las dos flores de loto abiertas de los extremos. Es cierto que el cesto neb aparece con mucha frecuencia decorando los registros inferiores o exergos de escarabeos, escaraboides y otros amuletos, pero hay excepciones a este uso generalizado. Es el caso de la presente pieza o de otra de Naucratis que muestra un pez (cf. Petrie 1886: lám. XXXVII, $n^{\circ}$ 62). Como hemos adelantado, probablemente el elemento que falta sea una palmeta o una flor de papiro abierta (cf. Vercoutter 1945: $\mathrm{n}^{\circ} 230$, con una flor de papiro y dos capullos a los lados en el registro superior; $\mathrm{y}^{\circ} 239$, con decoración floral en el registro inferior).

En definitiva, el escaraboide azul de Caura presenta rasgos que permiten encuadrarlo de forma general en el grupo de piezas egiptizantes presentes en ambientes fenicios occidentales y púnicos y, a la vez, una serie de caracteres que nos sugiere un origen mediterráneo oriental. En atención a las piezas análogas conocidas, su fecha puede llevarse a los siglos VII-VI a.C., si bien el contexto del Santuario III limita esta datación al siglo VII a.C. 


\section{Pieza 2. El escarabeo blanco del Santuario IV}

Se trata en este caso de un escarabeo de aspecto calizo, hecho de una pasta de gránulos de cuarzo $\left(\mathrm{SiO}_{2}\right)$ y cola animal (Franquelo y otros 2001). Mide 16,5 $\mathrm{mm}$ de longitud, 11,5 $\mathrm{mm}$ de anchura y $8 \mathrm{~mm}$ de grosor (fig. 8). Como el anterior, el tipo se fecha también en los siglos VII y VI a.C. Apareció en el extremo de un estrato compuesto en gran parte por ceniza, huesos de animales y fragmentos de cerámica escasamente rodados, un nivel interpretado como depósito intencionado de los restos de sacrificios llevados a cabo mientras estuvo en vida el Santuario IV, de fines del siglo VII a.C. o de comienzos del VI. De hecho, este paquete de sedimentos, que ocupa un estrecho espacio de forma trapezoidal situado entre el templo y las viviendas colindantes, llegó a colmatar en parte el muelle-banco que el muro perimetral del Santuario IV tenía adosado por su cara externa. Dicho pequeño recinto contaba con un murete de contención para que los vertidos de la «basura sagrada» no se esparcieran por la calle trasera del templo. Aun así, las cenizas rebosaron en dirección suroeste en determinado momento. Es en esta especie de cono de deyección, ya en la calle, donde se localizó este ejemplar (fig. 9).

Los motivos decorativos del escarabeo 2 se rellenaron de un colorante ocre a base de óxidos de hierro (hematites) y de plomo (massicot o minio) para que contrastaran bien con el fondo blanco. Muestran al dorso el esquema VI de Vercoutter (1945: 71). Una línea simple diferencia el protórax de los élitros, estando estos últimos separados por otra línea que se corta por el desgaste. Cada uno de los élitros presenta una pequeña incisión en forma de $\mathrm{v}$ que marca la callosidad humeral. A causa del deterioro que presenta, el clipeus está poco definido. Las patas se elaboraron de forma esquemática. Toda la pieza está atravesada por una perforación longitudinal.

En la cara ventral muestra un motivo iconográfico de una diosa ptéfora con las alas extendidas y rayadas simulando las plumas. La divinidad así representada viste una larga túnica decorada con líneas diagonales y paralelas a modo de pliegues, y está tocada con una especie de corona trapezoidal. Sostiene en cada ala una pluma como el signo egipcio para Ma'at. Curiosamente, ambos símbolos están orientados de manera opuesta. El exergo está ocupado con un motivo parecido al signo egipcio neb relleno también de una decoración rayada o reticulada. La escena no lleva ningún tipo de marco. En general, la

Fig. 8. Escarabeo blanco del Santuario IV

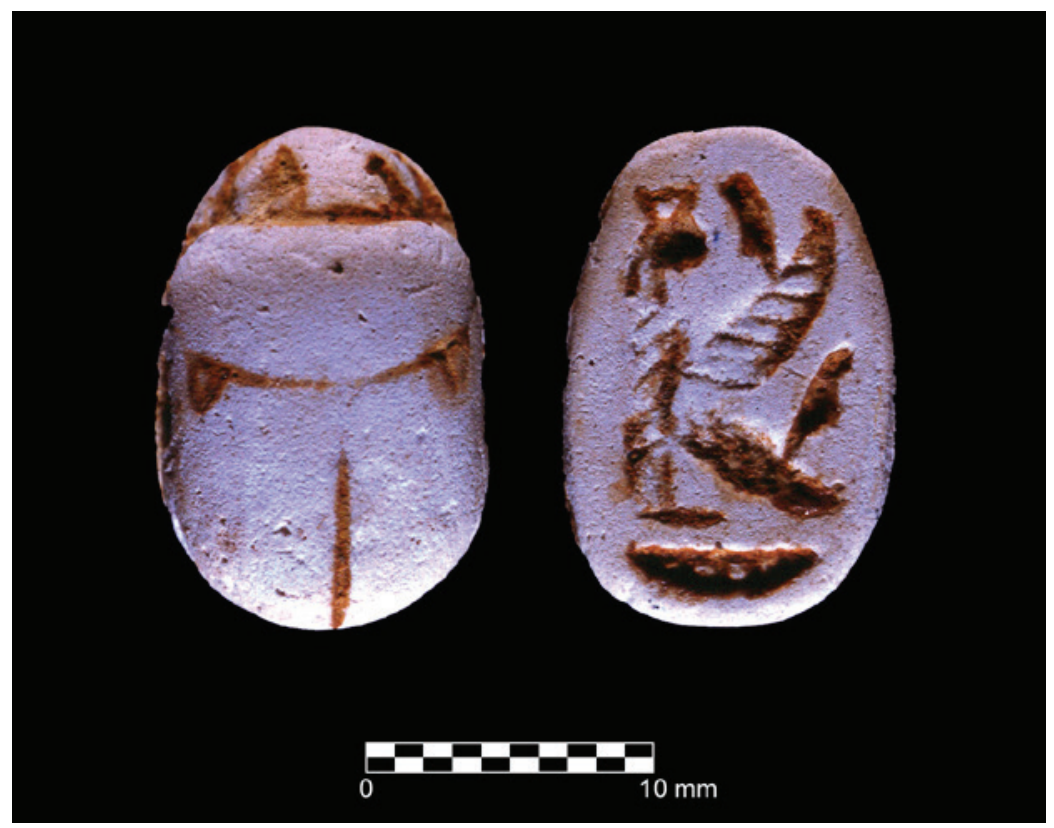

ISSN: 1133-4525 ISSN-e: 2255-3924

SPAL 14 (2005)

http://dx.doi.org/10.12795/spal.2005.i14.03 


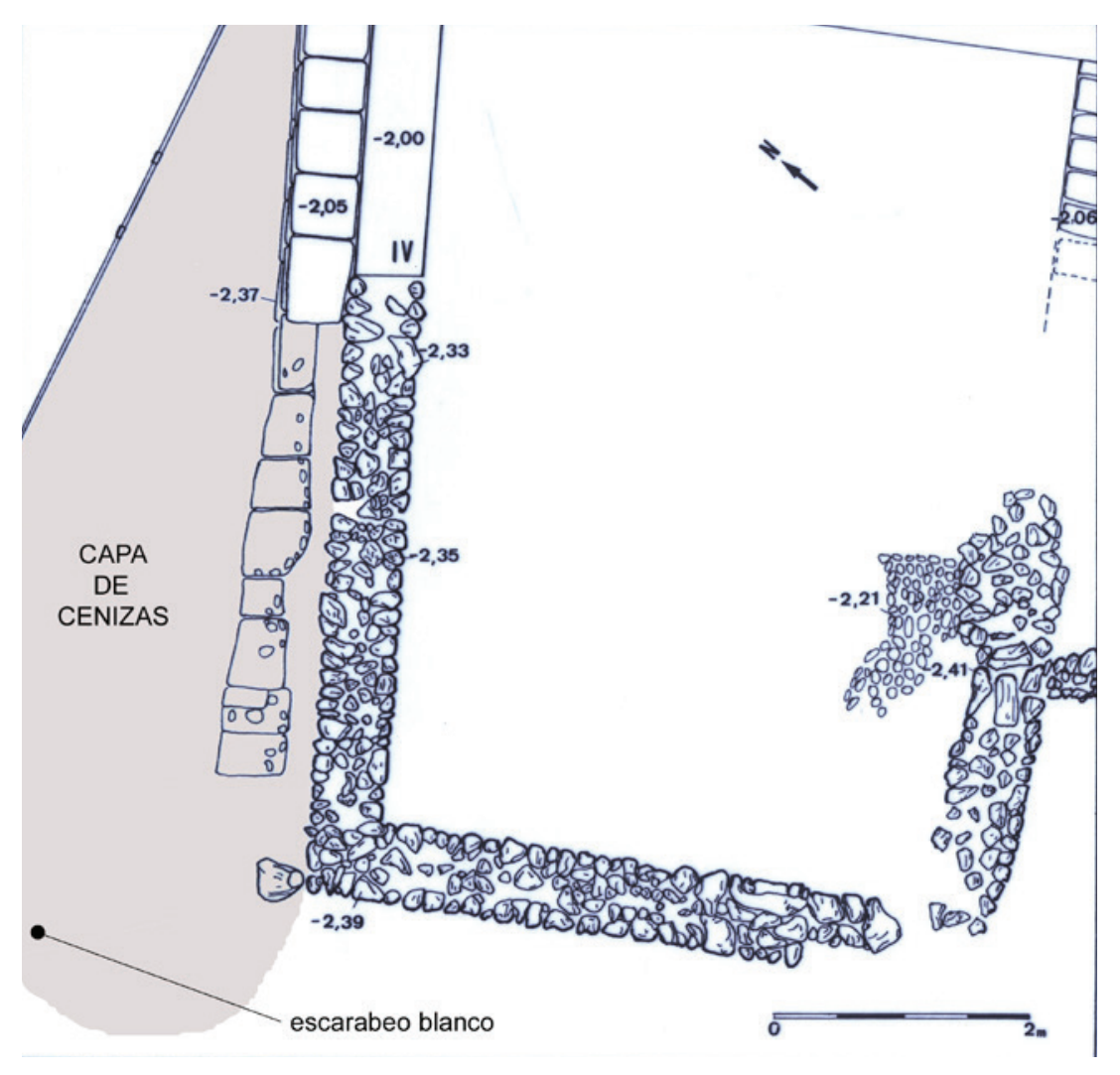

Fig. 9. Lugar de aparición de la pieza 2

técnica es tosca. El motivo está bastante deteriorado, especialmente en zonas como el pecho de la diosa o las bases de las alas, en las que los trazos han desaparecido por desgaste.

El motivo de la diosa ptéfora estuvo muy presente en el mundo feniciopúnico. La influencia egipcia está perfectamente clara en la pieza, no sólo porque el soporte es un escarabeo sino porque el tema iconográfico rememora a la diosa Isis, y ello a pesar de que el tema iconográfico isíaco, tan repetido en el mundo fenicio y púnico, no parece ser un motivo de origen egipcio, ya que la diosa casi nunca se representa en escarabeos egipcios (Vercoutter 1945: 88). Que la influencia egipcia en esta iconografía resulta evidente no presupone, en cualquier caso, que se mantenga el mismo significado egipcio en este contexto foráneo (cf. Ward 1994: 190-193: Marín 1996: 109-122). Por esta razón, la pieza puede catalogarse más bien como egiptizante. Aunque la diosa suele ir tocada con unos símbolos identificativos, tales como unos cuernos, un disco solar o una combinación de ambos elementos, en este caso lleva un tocado un tanto atípico: una especie de corona trapezoidal como las de las reinas o damas nobles de Egipto.

Las posturas adoptadas por Isis en los escarabeos son muy variadas, pudiendo aparecer representada sola, de pie y alada, arrodillada, sedente, acompañada de un acólito o un Osiris mumiforme. Sin embargo, el tipo más difundido es el de Isis amamantando a Horus (cf. Garbini 1994: 35). En nuestro caso, la actitud de la divinidad, con las dos alas extendidas y portando en ellas sendas plumas, cuenta con un buen número de paralelos (cf. Vercoutter 1945: $\mathrm{n}^{\text {os }} 4,404,649,658,693,695$ y 696) y responde a la imagen de la Isis que protege bajo sus alas a una figura osiriana, a Horus -tema que no falta en contextos fenicios (cf. Hölbl 1989: 322-323)- o incluso a un cartucho (cf. Vercoutter 1945: $\mathrm{n}^{\text {os }} 4,649,658,693,695,696$, entre otros). Se podría pensar que las dos plumas identificarían a la diosa con Ma'at, encarnación de la justicia y el orden. Sin embargo, ni Ma'at es una figura usual en 
los escarabeos feniciopúnicos ni la postura adoptada es representativa de la diosa, que suele aparecer sedente con el símbolo de la pluma sobre la cabeza. Las plumas no son un elemento ajeno en la iconografía, aunque generalmente hay una mayor preferencia por la flor de loto, que aparece tanto en manos de una diosa como entre las zarpas de leones, esfinges o grifos. Por tanto, y atendiendo a la lectura, podemos considerar que este prototipo egipcio de la diosa alada es un símbolo de protección en su sentido más amplio.

El motivo iconográfico del escarabeo no debe ser considerado meramente decorativo, pues el hecho de que haya aparecido asociado a un recinto sagrado induce a pensar que esta imagen, de carácter también religioso, ha de contener un mensaje específico. De hecho, como han señalado diversos autores, entre ellos Culican (1968: 50-103), Hölbl (1989: 318-319), Garbini (1994: 83-119) o Acquaro (1995: 183-189), los fenicios debieron conocer perfectamente la iconografía egipcia, la cual copiaron y reelaboraron para así expresar sus propias concepciones religiosas. Ciertamente, la carga mágica de los escarabeos deriva de la iconografía que portan. El valor mágico y apotropaico de estas piezas, en última instancia su valor religioso, es más importante que la función material y práctica que pudieron desempeñar (Ciafaloni 1995: 507-508). Por dicha razón, este ejemplar de Caura debió poseer un eminente carácter apotropaico y propiciatorio, pero ese carácter se dilata con el mensaje del icono: la pluma, al igual que la flor de loto, conserva el significado original de vida, y el hecho de que la diosa sostenga aquí unas plumas con sus alas extendidas rememora a la Isis maternal y protectora tan popular en el mundo fenicio y púnico. Si bien no podemos identificar con seguridad la diosa representada en esta pieza, podemos considerar que la semántica implícita es expresión sencillamente de la protección en su sentido más amplio.

\section{BIBLIOGRAFÍA}

ABAD, L. y SALA, F. (1993): El poblado ibérico de El Oral (San Fulgencio, Alicante) (Trabajos Varios del S.I.P. 90). Diputación de Valencia, Valencia.

ACQUARO, E. (1995): “I Fenici, Cartagine e l'Egitto", Revista di Studi Fenici XXIII, 2: 183-189.

AMORES, F. y ESCACENA, J.L. (2003): "De toros y de tesoros: simbología y función de las joyas de El Carambolo", en A. García-Baquero y P. Romero (ed.), Fiestas de toros y sociedad: 41-68. Universidad de Sevilla, Sevilla.

ARTEAGA, O.; SCHULZ, H.D. y ROOS, A.M. (1995): “El problema del 'Lacus Ligustinus'. Investigaciones geoarqueológicas en torno a las Marismas del Bajo Guadalquivir", Tartessos 25 años después, 1968-1993, Jerez de la Frontera: 99-135. Ayuntamiento de Jerez de la Frontera, Jerez de la Frontera.

AUBET, M.E. (1979): Marfiles fenicios del Bajo Guadalquivir. I, Cruz del Negro. (Studia Archaeologica 52). Universidad de Valladolid, Valladolid.

BELÉN, M. (1993): "Mil años de historia de Coria: la ciudad prerromana", en J.L. Escacena (coord.), Arqueología de Coria del Río y su entorno, en Azotea 11-12 (Monográfico de la Revista de Cultura del Ayuntamiento de Coria del Río): 35-60.

BISI, A.M. (1965): Il grifone. Storia di un motivo iconografico nell 'Antico Oriente mediterraneo (Studi Semitici 15). Centro di Studi Semitici, Roma.

CARRIAZO, J. de M. (1973): Tartesos y el Carambolo. Ministerio de Educación y Ciencia, Madrid.

CELESTINO, S. (1997): "Santuarios, centros comerciales y paisajes sacros", Espacios y lugares cultuales en el mundo ibérico, en Quaderns de Prehistòria i Arqueologia de Castelló 18: 359-389.

CIAFALONI, D. (1995): "L'art. Glyptique”, en V. Krings (ed.), La civilisation phénicienne et punique. Manuel de recherche: 501-508. E.J. Brill, Leiden.

ISSN: 1133-4525 ISSN-e: 2255-3924

SPAL 14 (2005)

http://dx.doi.org/10.12795/spal.2005.i14.03 
CORREA, J.A. (2000): “El topónimo Hispal(is)”, Philologia Hispalensis XIV: 181-190.

CULICAN, W. (1968): "The Iconography of some Phoenician sells and seal impressions", Australian Journal of Biblical Archaeology I, 1: 50-103.

DEL OLMO, G. (1998): Mitos, leyendas y rituales de los semitas occidentales. Trotta - Universidad de Barcelona, Madrid.

DELGADO, C. (1996): El toro en el Mediterráneo. Análisis de su presencia y significado en las grandes culturas del mundo antiguo. Universidad Autónoma de Madrid, Madrid.

DÍAZ TEJERA, A. (1982): Sevilla en los textos clásicos greco-latinos. Ayuntamiento de Sevilla, Sevilla.

ESCACENA, J.L. y IZQUIERDO, R. (2001): "Oriente en Occidente. Arquitectura civil y religiosa en un barrio fenicio de la Caura tartésica", en D. Ruiz Mata y S. Celestino (ed.): Arquitectura oriental y orientalizante en la Península Ibérica: 123-157. Centro de Estudios del Próximo Oriente - CSIC, Madrid.

FRANQUELO, M.L.; MEDINA, L. y VILLEGAS, R. (2001): "Estudio analítico de un escarabeo de piedra de procedencia egipcia hallado en unas excavaciones en el Cerro de San Juan de Coria del Río (Sevilla)", en B. Gómez y otros (ed.), III Congreso Nacional de Arqueometría: 631-638. Universidad de Sevilla - Fundación El Monte, Sevilla.

GARBINI, G. (1994): La religione dei fenici in Occidente (Studi Semitici 12). Università degli Studi «La Sapienza», Roma.

GARDINER, A. (1982): Egyptian grammar. Oxford University Press, Oxford.

GAVALA, J. (1959): La geología de la costa y bahía de Cádiz y el poema "Ora Maritima", de Avieno. Instituto Geológico y Minero de España, Madrid. Ed. facsímil en Cádiz, Diputación Provincial de Cádiz, 1992.

GORTON, A. F. (1996): Egyptian and egyptianizing scarabs. A typology of steatite, faience and paste scarabs from Punic and other mediterranean sites. Oxford Comité for Archaeology, Oxford.

HÖLBL, G. (1989): “Ägyptische Kunstelemente im phönikischen Kultukreis des 1. Jahrtausends v. Chr.: Zur Methodik ihrer Verwendung”, Orientalia NS 58: 318-325.

IONAS, I. (1984): "L'architecture religieuse au Chypriote Récent (Kition et Enkomi)", en G. Roux (dir.), Temples et sanctuaires (Travaux de la Maison de l'Orient 7): 97-105. Lyon.

KUKAHN, E. y BLANCO, A. (1959): "El tesoro de "El Carambolo"”, Archivo Español de Arqueología XXXII: 38-49.

LIPINSKI, E. (1984): "Vestiges phéniciens d'Andalousie", Orientalia Lovaniensia Periodica 15: 81-132.

LLOBREGAT, E.A. (1974): "El toro ibérico de Villajoyosa (Alicante)", Zephyrvs XXV: 335-342.

MARÍN, M.C. (1996): "Las relaciones entre Isis y Astarté: apuntes para su estudio", Isis. Nuevas Perspectivas (ARYS 4): 109-122.

MENANTEAU, L. (1982): Les Marismas du Guadalquivir, exemple de transformation d'un paysage alluvial au cours du Quaternaire récent. Université de Paris-Sorbonne, Paris.

PEREA, A. y ARMBRUSTER, B. (1998): "Cambio tecnológico y contacto entre Atlántico y Mediterráneo: el depósito de "El Carambolo", Sevilla", Trabajos de Prehistoria 55 (1): 121-138.

PETRIE, W.M.F. (1886): Naukratis: part I, 1884-1885. Tribner and Co., London.

POLANYI, K (1975): "Traders and trade", en J.A. Sabloff y C.C. Lamberg-Karlovsky (ed.), Ancient Civilization and Trade: 133-154. University of New Mexico Press, Alburquerque.

PY, M. y DIETLER, M. (2003): "Une statue de guerrier découverte a Lattes (Hérault)". Documents d'Archéologie Méridionel, 26: 235-249.

REVERE, R.B. (1976): “«Tierra de nadie»: los puertos comerciales del Mediterráneo oriental”, en K. Polanyi y otros (dr.), Comercio y Mercado en los Imperios Antiguos: 87-110. Labor, Barcelona. 
SANMARTÍN, J. (1994): “Toponimia y antroponimia: fuentes para el estudio de la cultura púnica en España”, en A. González Blanco y otros (coord.), El mundo púnico. Historia, sociedad y cultura (Coloquios de Cartagena, I): 227-247. Editora Regional de Murcia, Murcia.

VERCOUTTER, J. (1945): Les objects égyptiens et égyptisants du mobilier funéraire carthaginois, $\mathrm{P}$. Geuthner, Paris.

WARD, W.A. (1994) “Beetles in stone: the egyptian scarab”, Biblical Archaeologist 57, 4. 